\title{
A Fresh Look: The Social Competence of Information Science
}

\author{
Joseph E. Brenner \\ International Center for Transdisciplinary Research, Paris. c/o Chemin du Collège 1, 1865 Les \\ Diablerets, Switzerland; E-Mail: joe.brenner@bluewin.ch; Tel.: +41-24-492-2118; Fax: +41-24-492- \\ 2118
}

Accepted:

\section{Introduction. Three Crossroads}

In today's world, trends toward improvement in the quality of life are offset by a regression and degradation of the mental and social environment, both in part due to the massive role of information in the society. As at any crossroads, one has the possibility of going forwards or backwards. At this Socio-Political Crossroads, it is necessary to understand the way information operates to get on the 'right' road.

The science and philosophy of information as disciplines are also at another, closely related crossroads: they may develop in the direction of integration in an Informational Turn, a new way of Informational Thinking as proposed by $\mathrm{Wu}$ Kun [1] that can support efforts toward a Global Sustainable Information Society, in the term of Wolfgang Hofkirchner [2]. Alternatively, they may diverge or regress in the direction of increasingly socially irresponsible specialization and scholasticism. This is, then, a Transdisciplinary Crossroads.

A third crossroads, inseparable from the first two, involves the direction of development of the science and philosophy of information as metaphysics. It is a Metaphysical Crossroads that includes a definition of the dynamic relation of man to the universe. Like the other two, there is a positive branch ("Turning One's Head" as Gerhard Luhn describes it [3]) leading toward less dysfunction at the individual and social level. The negative branch implies an on-going blockage of ethical development of the society.

In this paper, I discuss three aspects of information as they relate to a potential information commons. One is the political dimension and the potential commitment to some form of action in which practitioners of information science could be involved. The second is my dialectic logic in reality (Logic in Reality; LIR [4]) that in my view best describes the nature and evolution of information; and the third is the relation of that logic to the dialectic logic of Hegel in some of its 
current interpretations, as discussed by Fuchs [5]. In this view, Logic in Reality provides a link to science, hence its scientific support of initiatives for the common good. This paper is, accordingly, a response to the first question posed in ICT\&S 16, namely, "What contradictions, conflicts, ambiguities and dialectics shape the $21^{\text {st }}$ century information society?"

\section{Dialectical Philosophy and Logic}

\subsection{The Problem of Logic - Again and Still}

The current social, political and economic system, with its failures and lack of ethics is unfortunately supported, directly or indirectly, by the tenets of standard philosophy and in particular its logic. In many theories of society and economics, the underlying logic is essentially bivalent classical logic, a logic of "exclusion", mirroring the absolute separation between premise and conclusion, set and member of set and the principle of exclusivity in standard category theory. The situation has scarcely evolved since 1936, when Norris stated [6] “...practical and technological problems simply cannot be solved by use of Aristotelian logic alone. This is not a logic of forward-looking or intentional activity whether practical or technological."

For Jacques Ellul in the 1960's [7], the term logic characterized primarily the dysfunction of the society, as in "the implacable logic of the market" that exacerbates the separation between the global networks, for example in Manuel Castell's conception [8], of capital flows and the human experience of disenfranchised workers. Barinaga and Ramfelt [9], quoting Castells, state that one of the challenges of the society is that its very logic is based on an idealized, one-sided conception of society that excludes an important part of the world population. Any intellectual approach that weakens, deconstructs or discredits this ideology and proposes workable, socially acceptable alternatives is therefore to be welcomed.

In 2006, Christian Fuchs suggested [10] the need for a new functional "logic of self-organization" as a necessary feature for models to be able to deal with normative aspects of development, so that the "meaning" of the meaning of information is not ambiguous, but includes a moral dimension. At this Conference, Section ICT\&S 3 on the Internet, Commodities and Capitalism will deal with the commodity logic of contemporary capitalism.

In a 2009 paper [11], I described further the essential components of my "logic of and in reality" (LIR), and showed that it had the capability of addressing and illuminating issues raised by Hofkirchner, Fuchs et al. in their evolutionary "Salzburg Approach". LIR founds a logical approach to the evolution of both groups and individuals and their interaction, and to the negative as well as the positive aspects of current technological developments. LIR provides a new logical interpretation of key concepts in social theory including morality, cooperation and conflict, grounding them in physical reality and authorizing patterns of inference. The term "evolutionary" is discussed in terms of similarities and differences with biological evolution; LIR offers a logical explication and expansion of Fuchs' statement that nature and society are both identical and non-identical. 
Logic in Reality is both dialectical and transcendental in the sense of Hegel. It is dialectic in that the law of non-contradiction fails and transcendental in that it 'straddles' the opposition between subject and object [6]. Such a logic is close to an ontology, that is, it says something about the nature of things. Of course, the conceptual structure of reality that LIR offers includes information to which Hegel did not have access. None of it, however, is inconsistent with the principle of contrastive dialectics but rather reinforces it. As I have pointed out elsewhere, LIR supplements Hegel by adding a descending dialectic to Hegel's ascending one and incorporates a necessary ground at the lowest physical level of reality. Logic in Reality makes it possible to enter the dialectic process from science itself, that is, the entities postulated and in part proven by science (other than to hard-core anti-realists), for example quantum physics, are compatible with a philosophical sublation and indeed isomorphous to it. Elements and their contradictions or oppositions follow the same pattern of evolution and emergence.

\section{3 Žižek and Fuchs: A Fresh Look}

The sociologist Slavoj Žižek is a devastating critic of the current late-capitalist politico-economic system and its "pseudo-natural logic". Calling our society an Information Society is already an ideological statement, although not recognized as such, since it suggests degrees of freedom from capitalism that do not exist. In a major book, Living in the End Times [12], Žižek shows how this antihumanist system is reflected in current art - literature and cinema - even in its 'New Age' form supposedly opposed to the current capitalist paradigm. One must reject the ideology at work in technology and the artificial solutions it proposes. However, "It is not enough to demand an ecological reorganization of capitalism, but neither will a return to a pre-modern organic society and its holistic wisdom work." Žižek thus calls for a "fresh look" at the uniqueness of our situation, a concrete social analysis of the economic, political and ideological roots of our problems. A reconceptualization of dialectical logic is necessary to which Logic in Reality may contribute.

In the paper prepared for this Summit referring to Žižek, Fuchs [5] states that capitalist society operates in such a way as to maintain the continuity of capitalism as a system in the face of contradictions resulting from the discontinuities which are a consequence of the ICTs. In Lupascian terms, 'energy' needs to be added to permit a resolution of these contradictions at higher level of reality, in other words, convert the ICTs to an information commons, a non-capitalist information society. Logic in Reality, in my view, should be the preferred language to discuss complex interrelated contradictions and dialectics of dialectics, a term used by Lupasco [13].

\section{What Has Happened to the Common Good?}

The environments for human existence which can be considered as components of the common good are the following: 1) the informational environment, defined by the revolution in the information and communications technologies (ICTs); 2) the natural global environment which, apart from some local improvements, is undergoing massive and possibly irreversible degradation; 3) the local socioeconomic environment in which individual human beings evolve. 
In a recent book [14], whose title is that of this section, François Flahault shows that social reciprocity and coexistence are the essential requirements for a satisfactory individual life, defining the real, non-economic "common good". However, the necessary codification of the rights of individuals, in the Universal Declaration of Human Rights in the aftermath of World War II, is now interpreted in a context of market-driven globalization of the ICTs, leading to a drastic and inhuman devaluation of the common good. What is new and problematical in the environments is not technology - science and engineering per se - but the ever-increasing space, material and mental, that is abusively occupied by the artifacts of technologies and their misdirection to individual selfish goals. Unless philosophers and logicians as well as scientists address these issues, they will have failed to address the reality of our world.

\section{The Social Competence of Information Science}

What is thus missing in the information science literature (and in the first part of this memorandum) is the social-political dimension, the social, economic and political context in which any application of a more ethical philosophy theory must be made. This paper may be thus considered as having aspects of a social critique, a 'social philosophy' in the sense of the neo-Marxist Franck Fischbach [15]. I see the entire Summit as social philosophy in this sense. It is an ethical reflection on an informational commons as a necessity for that commons, and it is at the same time a political reflection on the process of struggle to achieve it. Fischbach's social philosophy does not separate the social from the political, sparing the effort to put them back together subsequently.

The complex entity constituted by the participants in this Summit and their transdisciplinary contributions confers a competence and a unique credibility on them. Practitioners of Information Science start with an advantage of being at the heart of the defining technology of our "Information Age", and I suggest that this is recognized by every user of the technology, that is, everyone.

\section{Conclusions}

In the perspective outlined here, Logic in Reality is the thread that runs from the foundations of the nature of information in the physical structure of the world, through the informational characteristics of human beings to those of the society that defines the context for human existence as a social animal. LIR is therefore a new tool to use in the 'struggle to learn how to struggle'. In the metaphilosophy of information of $\mathrm{Wu}$ Kun [16], transdisciplinary informational activities have as a direct consequence the weakening of centralized governments and political institutions and, correspondingly, a strengthening of a commons.

Finally, encouraged by Fuchs's demonstration of the importance of Heraclitus' version of dialectics, I close with a fragment that I feel is à propos to a Summit about an information commons: "Fragment 2: Accordingly, one ought to follow what is common, that is to say, what is universal. For the universal Word is common to all. ..." 


\section{References}

1. Wu, K. 2010. The Basic Theory of Philosophy of Information. Paper, 4th International Conference on the Foundations of Information Science, August, 2010, Beijing.

2. Hofkirchner, W. 2013. Emergent Information; A Unified Theory of Information Framework. World Scientific Publishing Company: Singapore.

3. Luhn, G. and G. Hüther. 2014. Wende im Kopf. Radebeul, Göttingen: unpublished manuscript.

4. Brenner, J. E. 2008. Logic in Reality. Springer: Dordrecht.

5. Fuchs, C. 2014. The Dialectic: Not just the Absolute Recoil, but the World's Living Fire that Extinguishes and Kindles Itself. Reflections on Slavoj Žižek's Version of Dialectical Philosophy in Absolute Recoil: Towards a New Foundation of Dialectical Materialism. triple-C 12(2): 848875.

6. Norris, O. O. 1936. The Logic of Science and Technology. Philosophy of Science 3 (3), pp. 286306.

7. Lovekin, D. 1977. Jacques Ellul and the Logic of Technology. Man and World 10(3), 251-272.

8. Castells, M. (2004). The Information Age: Economy, Society and Culture. Volume II The Power of Identity. Blackwell Publishing: Malden/Oxford/Carlton.

9. Barinaga, E. and L. Ramfelt. Kista - The Two Sides of the Network Society. In: Networks and Communications Studies, 18 (3-4):225-244.

10. Fuchs, C. 2006. The Dialectic of the Nature-Society System. Triple C, 4 (1), 1-39.

11. Brenner, J. E. 2009. Prolegomenon to a Logic for the Informational Society. Triple C, 7(1), 38-73.

12. Žižek, S. 2011. Living in the End Times. Verso: London.

13. Lupasco, S. 1987. Le principe d'antagonisme et la logique de l'énergie. Editions du Rocher: Paris. (Originally published in Paris: Éditions Hermann, 1951).

14. Flahault F. 2011. Où est passé le bien commun? Paris: Mille et Une Nuits.

15. Fischbach, F. 2009. Manifeste pour une philosophie sociale. Éditions La Découverte: Paris.

16. Wu K. and J. E. Brenner. 2014. The Informational Stance: Logic and Metaphysics. Part II From Physics toSociety. Logic and Logical Philosophy 23:81-108.

(C) 2015 by the authors; licensee MDPI and ISIS. This abstract is distributed under the terms and conditions of the Creative Commons Attribution license. 